\title{
Electronic health records across the nations
}

\author{
KEYWORDS \\ Electronic health \\ records; \\ Personal health \\ records; \\ E-health
}

\begin{abstract}
The focus of this special issue is to describe and compare electronic health record initiatives across different nations. We decided to include personal health records as well because these records also span the international playing field. In total, seven studies are presented from four different countries. This editorial provides some overall conclusions and an overview as a benchmark for further study.

(c) 2015 Fellowship of Postgraduate Medicine. Published by Elsevier Ltd. All rights reserved.
\end{abstract}

\section{Editorial}

For two decades, healthcare organizations struggle to develop and introduce electronic healthcare records. National initiatives have severe acceptation problems and local initiatives have severe diffusion problems. In this special issue, the status quo in four different countries is visited in seven papers. We also show personal health records as an international development as a future perspective.

Table 1 gives an overview of the papers in this special issue. First the USA situation will be shown from three different angles. Then we look at the German and Austrian developments on EHR, the first just in its first phase and the second already further in development. In the Netherlands, e-health is well developed but still the national initiatives are not successful yet. Within the hospitals and GP practices a high level of EHR is reached.

Cellucci, Cellucci, Stanton, Kerrigan \& Madrake studied the diffusion of EMRs in psychology training clinics and their study indicates rapid growth. Adoption and diffusion are similar to previous studies of physician practices. Cost, IT support and system non-fit were primary concerns noted by non-adopters. Clinics adopt EMR to prepare future psychologists to work in healthcare settings, but few clinics had progressed to consider how EMR functions might enhance care.

Wiggins, Peterson \& Moss reported low use of EHR and HIT internally, and between outpatient settings. They stated that there is no apparent relationship between CEO's EHR expectations and beliefs and use of EHR. Most ASCs continue to rely on fax to share patient information between providers. ASCs report low use of CPOE and electronic prescribing and continue to document patient care in paper medical records, not in an EHR.

Gan and Cao conducted a survey of students in health organization management. The student responses indicate a strong relationship between task technology fit and the social contagion of EHR. Consequently, they propose that EHR developers should consider healthcare diffusion as it is different than in other organizations. For policy makers, they recommend identification of the most influential stakeholder in the region and start motivation and diffusion with him or her.

Based on a case of the German Electronic Health Card, Kloecker and Veit build a qualitative study assessing the national infrastructure of German e-health. They note failures that have occurred in the past and propose that failure or success is influenced by the many stakeholder interests involved. They recommend that an understanding of the potential influences of the various stakeholders may

Table 1 Research overview.

\begin{tabular}{|c|c|c|}
\hline & Local EHR & National EHR or PHR \\
\hline USA & $\begin{array}{l}\text { Celucci et al. } \\
\text { Wiggins et al. }\end{array}$ & Gan and Cao \\
\hline Germany & & Kloecker and Veit \\
\hline Austria & Steiniger & \\
\hline Netherlands & & $\begin{array}{l}\text { Spil and Klein } \\
\text { Michel-Verkerke et al. }\end{array}$ \\
\hline
\end{tabular}


aid in identification of potential implementation issues and risks to successful outcomes.

Steiniger took a different perspective when she studied the Austrian EHR developments. She proposed that the physician is the most important stakeholder in the diffusion of the EHR and uses TAM and Social Equation theory to study physician support of EHRs. The results are that social influence, HIT experience, and privacy concerns had a significant effect on the perceived usefulness of EHR systems, which in turn had an impact on a positive attitude as well as the intention to use such a system.

Spil and Klein performed a study in which they interviewed 83 potential users of personal health records and concluded that it will be difficult for Apple and Samsung to conquer the market where Google failed and Microsoft (HealthVault) struggles. The relevance of such apps for healthy people is not clear and there are severe trust and privacy issues to be dealt with.

Michel-Verkerke, Stegwee and Spil studied 10 years of EHR development in the Netherlands and discussed the distinctions between Medical Technology, Administration and Care Process. They note that these three areas are separate and distinct without much overlap. They proposed that six Ps have to be met to create an active EHR that spans the three areas. Three Ps concern the type of users, namely Patients, Professionals or the Public in general. Three other Ps concern the type of action, namely Purpose, Process and Precondition.

\section{Author statements}

\section{Ethical approval}

Not required.

\section{Funding}

None.

\section{Competing interests}

None declared.

Ton AM Spil*

University of Twente, The Netherlands E-mail address: a.a.m.spil@utwente.nl

Leigh W. Cellucci

East Carolina University, USA E-mail address: cellucci@ecu.edu

*Corresponding author. 